\title{
A circulação de sentidos: o ir e vir dos sentidos de família em uma peça publicitária televisiva
}

p. $114-128$

\author{
Lucas Martins Flores ${ }^{1}$ \\ Verli Fátima Petri da Silveira ${ }^{2}$ \\ Aracy Ernst $^{3}$
}

\section{Resumo}

As peças publicitárias são reconhecidas por sua conformação aos sentidos estabilizados socialmente, dentre elas, as "de margarina” expõem, via de regra, a família considerada padrão. Os dicionários, por sua vez, são caracterizados pelo registro dos sentidos consolidados das palavras: eles são os "guardiões" da língua. No entanto, vistos como discursos, tanto as peças publicitárias, quanto os dicionários podem provocar efeitos de sentido imprevisíveis. Através da observação da circulação de sentidos da palavra "família" em um comercial de margarina, buscamos estabelecer relações entre os sentidos a ela vinculados tanto na mídia televisiva quanto no dicionário. Com base na Análise de Discurso pecheuxtiana, propomos que a propaganda analisada, cuja estruturação articula música, monólogo e imagem, mobiliza sentidos presentes na memória do sujeito e provoca ilusórios efeitos de sentido.

Palavras-chave: Publicidade televisiva. Família. Dicionário. Interpretação. Análise de Discurso.

\section{THE CIRCULATION OF MEANINGS: GOING AND COMING OF THE MEANING OF FAMILY IN AN TELEVESIVE ADVERSITING PIECE}

\begin{abstract}
Advertising pieces are recognized by their conformation to socially stablished meanings. Amongst those, the "margarine" ones present, as a general rule, a "model" family. Dictionaries, in their turn, are characterized by registration of consolidated meaning of words: they are the "guardians" of the language. However, seen as discourses, not only the advertisements, but also the dictionary, may cause unpredictable effects of meaning. By the observation of the circulation of meanings to the word "family" in a margarine commercial, relations are stablished between the meanings related to the word by the advertisement as well as by the dictionary. Based on Pêcheux Discourse Analyses, it is proposed that in the analyzed advertisement, which structure connects music, monologue and images, mobilize meanings present in the memories of the subjects and provokes deceptive effects of meaning.
\end{abstract}

Keywords: Television publicity. Family. Dictionary. Interpretation. Discourse Analyses.

1 Professor do Instituto Federal Farroupilha - Campus Jaguari (IFFar - Ja). Doutorando em Letras (PPGL/UFSM). Bolsista do PIIQP do IFFar - Ja. E-mail: <lucasmflores@gmail.com>.

2 Professora associada II, DLV/Laboratório Corpus/ PPGL/UFSM.

3 Professora Titular do Programa de Pós-Graduação em Letras da Universidade Católica de Pelotas e Coordenadora do Laboratório de Estudos em Análise de Discurso (LEAD). 


\section{Introdução}

O discurso, concebido como "efeito de sentido entre os pontos A e B" (PÊCHEUX, [1969] 2010a, p. 81), é uma noção essencial para a compreensão dos processos de produção de sentidos em diferentes materialidades - sejam elas isoladas para uma determinada análise, sejam elas postas em relação em outra perspectiva de análise. Em geral, podemos dizer que as materialidades discursivas engendram diferentes níveis de complexidade, cada uma delas é trabalhada para que produza evidências de sentidos entre os interlocutores, mas isso escapa ao sujeito que produz o discurso, e a polissemia instala-se em todos os lugares. Em nosso entender, o discurso publicitário "atua no social a partir de uma formação ideológica e histórica determinada que delineia a (re)produção de sentidos mobilizada em suas práticas" (MEDEIROS, 2013, p. 50), é um discurso rico em complexidades que se expandem para diferentes recursos midiáticos, exemplar para a produção de determinados sentidos, silenciando tantos outros possíveis.

Para este estudo, elegemos uma peça publicitária produzida para a televisão brasileira, disponível hoje na internet ${ }^{4}$. Trata-se de uma peça publicitária da marca Sadia, dando ênfase às comidas prontas ou pré-prontas que tal marca produz e trazendo como mote o conceito de família, ao qual são vinculadas as características do produto anunciado. Essa peça nos chamou a atenção, inicialmente, por trazer à baila o conceito de família ${ }^{5}$ dicionarizado ${ }^{6}$, buscando descontruir o conceito institucionalizado e abrindo para outros efeitos de sentidos. Para além da mobilização do conceito de família dentro e fora do dicionário, a peça publicitária produziu em nós um efeito de sedução pela música que traz como pano de fundo, e que, às vezes, assume o papel central. Trata-se de uma música em Língua Inglesa, o que exigiu de nós uma pesquisa um pouco mais aprofundada, como apresentaremos no decorrer deste estudo.

A peça publicitária da Sadia é nosso objeto de estudo e nos deteremos em três elementos constitutivos dos processos de produção de sentidos que fazem dela o que ela é: a) a música, enquanto discurso; b) o monólogo que a personagem principal apresenta - texto, enquanto discurso em relação com c) as imagens, enquanto discurso. Cada um desses elementos tem um funcionamento muito específico, imprescindível para que se efetivem as evidências de sentidos.

\section{Sobre as Condições de Produção}

A fim de compreendermos as condições de produção da peça publicitária em estudo e de relacionarmos tal discurso com os sentidos em circulação atualmente, identificamos dois discursos em pleno funcionamento. Nosso recorte parte de agosto de $2009^{7}$, quando a marca

4 Pode ser acessada por meio do link: <https://www.youtube.com/watch?v=sOsL-JCwbRM>.

5 Família é também o mote para análise discursiva empreendida por Lucas Flores em sua dissertação de mestrado intitulada "Você se vê naquilo que vê? Representações de família em comerciais e seus efeitos de sentidos" UCPel, 2014, orientado pela Professora Dra . Aracy Graça Ernst, disponível em http://tede.ucpel.edu.br:8080/jspui/bitstream/tede/368/1/Lucas\%20 Flores.pdf

6 O dicionário tem sido objeto de estudo da Profa. Dra. Verli Petri nos últimos 10 anos. Cf. Petri (2010); (2012); 2014); (2016).

7 Todas as próximas informações sobre o comercial em análise foram retiradas de: <http://www.memoriadapropaganda.org. br/Noticias/Noticia.php?newsId=20090808B\&Img=2> Acesso em: dezembro de 2013. 
"Sadia” lança uma campanha com o slogan "A Vida com S é Mais Gostosa". Nessa campanha, todas as peças publicitárias têm como elemento central a letra "S", ícone da marca Sadia. No comercial desse ano, a letra "S" além de se tratar da letra que forma o plural das palavras da Língua Portuguesa, representa, na opinião do diretor de marketing Eduardo Bernstein, a capacidade que a marca tem de reunir as pessoas em diferentes grupos, sejam famílias formadas por laços de sangue ou por grupos de afinidade.

Nas palavras de Eduardo Bernstein (2009),

[...] nossa nova campanha representa uma evolução para a marca em seu objetivo de tornar a vida das pessoas ainda mais gostosa, já que continua a fortalecer seus valores essenciais e avança a construir o conceito de pluralidade de forma alegre, gostosa e divertida. [...] Com esta campanha, pretendemos mostrar como a Sadia pode unir as pessoas ao estar presente no cotidiano de todos os tipos de família, desde aquelas formadas a partir de laços de sangue - tradicionais ou não - às formadas por afinidades.

A Sadiaidentificou, "por meio de pesquisas", importantes transformações ocorridas no modelo da família ao longo dos anos, informa Eduardo Bernstein. "O formato tradicional - com pai, mãe e crianças - foi alterado em muitos lares, dando lugar a famílias mais enxutas, com a presença de um filho único, ou a família mais extensas, com novos agregados, fruto de casamentos anteriores". O diretor da marca Sadia acrescenta que:

[...] as longas jornadas de trabalho, o aumento do número de divórcios e as mudanças nas relações de hierarquia dentro do lar provocaram mudanças na estrutura familiar e, consequentemente, nos hábitos, valores e opiniões sobre as relações em família. Desta maneira, o conceito de família foi ampliado e extrapolou os laços sanguíneos, com uma valorização cada vez maior das relações independentes do vínculo biológico. Essas novas famílias são baseadas na empatia, identificação, amizade, convivência de seus membros, como é o caso dos grupos de amigos de um escritório, faculdade, escola ou academia, ou até dos amigos virtuais criados dentro das redes sociais da internet (BERNSTEIN, 2009).

Dessa forma, percebemos que a marca Sadia percebeu a possibilidade de explorar uma temática que, de uma forma ou outra, toca o sujeito telespectador. O que é família? Quem é nossa família?

De outra parte, já em outubro de 2013, a Câmara de Deputados aprovou o Estatuto da Família, projeto de lei que tenta definir o que pode ser considerado uma família no Brasil, além de estabelecer regras jurídicas para qual tipo de grupo de pessoas pode ser chamado de família. Com dezessete votos favoráveis e cinco contrários, a Comissão aprovou a PL 6583-13, que define família como "entidade familiar como núcleo social formado a partir da união entre um homem e uma mulher ${ }^{8}$, por meio do casamento estável, ou ainda por comunidade formada por qualquer dos pais e seus descendentes" (BRASIL, 2013) $)^{9}$.

Em resposta a esse estatuto, o dicionário Houaiss lançou, em abril de 2016, uma campanha para (re)definir o verbete "família". O

8 O reconhecimento de casamento entre pessoas do mesmo sexo no Brasil como entidade familiar, por analogia à união estável, foi declarado possível pelo Supremo Tribunal Federal (STF) em 5 de maio de 2011 no julgamento conjunto da Ação Direta de Inconstitucionalidade (ADI) n. ${ }^{\circ}$ 4277, proposta pela Procuradoria-Geral da República, e da Arguição de Descumprimento de Preceito Fundamental (ADPF) n. ${ }^{\circ}$ 132, apresentada pelo governador do estado do Rio de Janeiro. Desta forma, no Brasil, são reconhecidos às uniões estáveis homoafetivas todos os direitos conferidos às uniões estáveis entre um homem e uma mulher.

9 Disponível em: <http://www.camara.gov.br/proposicoesWeb/prop_mostrarintegra?codteor=1159761\& filename=PL+6583/2013>. Acesso em: 01 ago. 2017. 
projeto promovido pela agência NBS em parceria com o dicionário Houaiss recebeu mais de três mil sugestões enviadas por internautas por meio da campanha \#TodasAsFamílias ${ }^{10}$, ficando assim definido: "núcleo social de pessoas unidas por laços afetivos, que geralmente compartilham o mesmo espaço e mantêm entre si uma relação solitária".

É preciso observar que a peça publicitária tenta provocar um efeito de sentido de totalidade e de universalidade, como se todas as famílias possíveis fossem contempladas no comercial de televisão. Desse modo, concordamos com Medeiros (2013, p. 50), quando afirma que o "discurso é efeito de sentido do lugar da mídia no social e das relações de poder aí imbricadas". O mesmo processo acontece quando o dicionário Houaiss, após campanha, se propõe a incluir as mais de três mil sugestões do conceito de família em poucas linhas de um "novo" verbete. É nesse lugar que encontramos espaço para tal estudo: espaço do dizível em relação ao não dizível, mostramos, por meio de nosso gesto interpretativo, como o discurso de uma peça publicitária sobre família regulariza, desliza, falha, tocando o sujeito telespectador em pleno século XXI.

\section{Sobre a música}

Outro aspecto do comercial que merece atenção é o que se refere à música de fundo usada e que, às vezes, torna-se o dizer do comercial. A música, intitulada Love is the truth ${ }^{11}$, trata de amor, afirmando que ele está em toda parte, basta observar; e menciona o amor de mãe, pai, filho, filha, motivando o sujeito ouvinte/ telespectador a cuidar desse amor, sendo a "coisa" certa a fazer. A música escrita por Jack White, integrante da banda White Stripes, foi veiculada e produzida especialmente para um comercial da Coca-Cola ${ }^{12}$ na Austrália e na Inglaterra. No Brasil, é feita essa transferência para a Sadia, e o comercial é outro, permanecendo a ideia de amor e de "reunião" por meio do produto anunciado.

Nessa breve descrição, observamos que o comercial, apesar de trazer um imaginário contemporâneo de família - àquela em que os membros são os amigos, os colegas de trabalho, de natação, de brincadeiras de infância -, também afirma que o amor de mãe, pai e membros sanguíneos da família têm um amor especial que precisa ser cuidado. Estaria aí a família em desordem, sem lei simbólica, como afirmado por Roudinesco (2003), como a família dos tempos atuais? Não diríamos em desordem, mas uma possível tentativa do comercial em mostrar a normalidade dessas configurações de família que a sociedade adota para dar conta dessa falta de lei simbólica. Essa lei simbólica, de que trata Roudinesco (2003) representa a falta de ordem paterna, historicamente exercida pela posição pai: o progenitor e mantenedor da instituição social família. "O homem estaria se reduzindo a uma mercadoria no seio de uma economia liberal" (ROUDINESCO, 2003, p. 11), afinal, todas as famílias são iguais, a peça publicitária tenta iludir o sujeito telespectador de que todas as famílias, sejam elas da forma como forem, são todas iguais, basta serem unidas e terem, como diz a música,

10 Disponível em: <http://todasasfamilias.com.br/>.

11 Tradução nossa: Amor é a verdade.

12 Disponível em: <http://ovolume.wordpress.com/>. Acesso em: 01 set. 2014. 
"amor é a verdade".

A seguir, apresentamos a adaptação da

música utilizada no comercial e sua tradução.

\begin{tabular}{l}
\hline Love is the truth - Jack White \\
(Versão do Comercial) \\
One thing youll leam, you can bet \\
Is that love is as good as it gets \\
And youll get more if you give it \\
You can say that love's not really there \\
And pretend that you don't really care \\
But youll do better to live it \\
In the arms of a mother and father \\
In the eyes of a son or a daughter \\
It's there if you want it \\
Oh shohoh \\
In the water the sun passes through \\
In the air that is all around you \\
It's there if you want it \\
Oh ghohoh \\
It's everywhere \\
You just have to care \\
It's the right thing to do \\
And you know it \\
And it's inside of you \\
So just show it \\
Love is the truth \\
Ba babababa \\
And it's inside of you \\
Ba babababa \\
It's the right thing to do. \\
\end{tabular}

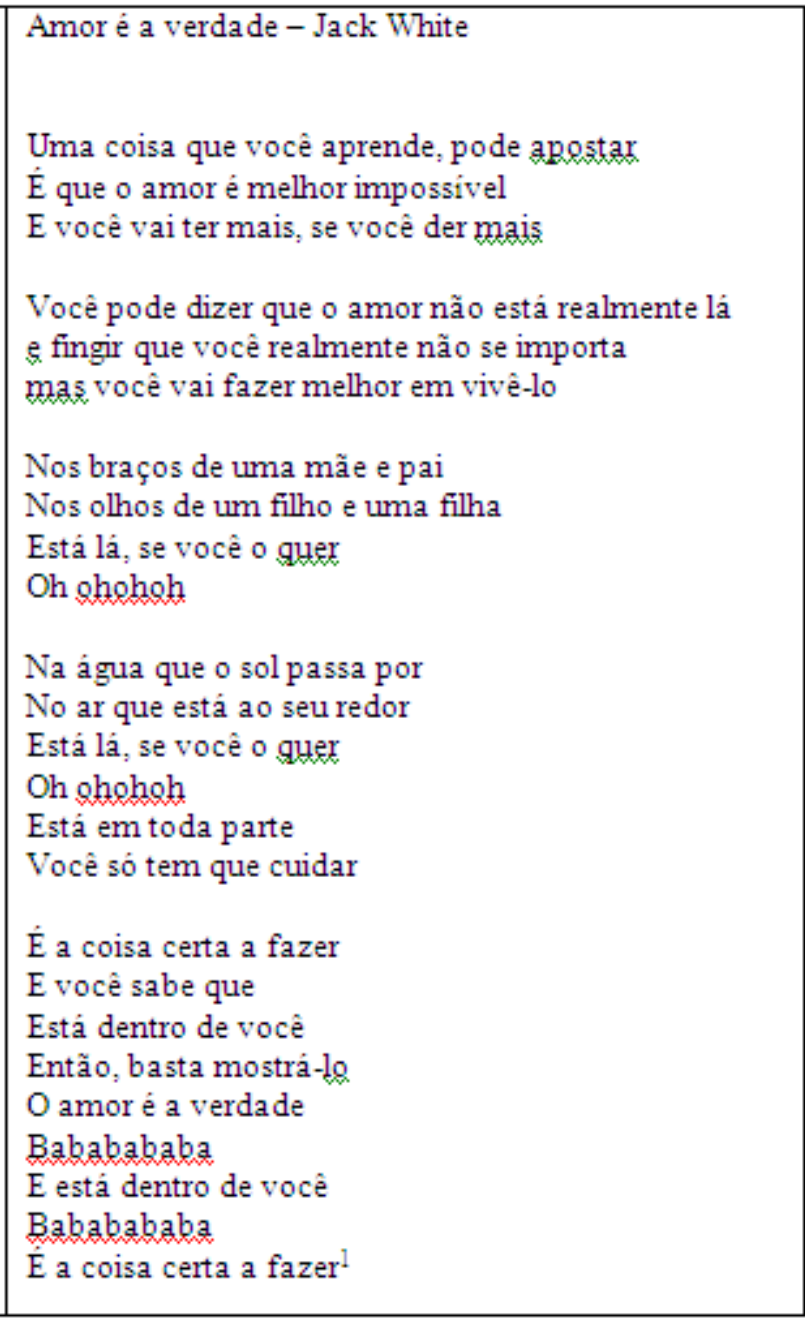

13 Tradução realizada pelos autores. 
No decorrer da peça publicitária, por muitos momentos, a música assume um papel que vai além do pano de fundo. Ela atravessa o monólogo, principalmente em partes que falam do amor, interpelando o sujeito telespectador a respeito do fato de que família é isso que mostramos (nas imagens) e falamos (no monólogo), mas também pode ser tantas outras coisas, porque, como diz a (música), "love is the truth" (amor é a verdade).

\section{Sobre o monólogo e as imagens... música de fundo: possíveis relações}

A peça publicitária analisada foi elaborada por Marcello Barcelos, Rafael Urenha, Ana Laura Gomes e Fernando Rodrigues. O fato de demonstrar diferentes formações familiares justifica a escolha desse comercial para representar essa Formação Ideológica da família dos dias atuais, pois permite ao sujeito telespectador se confrontar com diferentes imaginários de família. Assim, compreendemos que a ideologia estaria trabalhando em prol de uma ideia dominante de que todos são família, fazem parte de uma família, logo estão em pé de igualdade. O comercial carrega em si as marcas do apagamento das diferenças, levando o público em geral a se identificar e consumir Sadia.

Assim, tentamos mostrar, por meio de nosso gesto interpretativo, as sequências discursivas (SD) separadamente em cada figura para constituir um recorte discursivo do todo do comercial e, a partir da relação - música-imagemenunciado -, explicitar as possíveis tomadas de posição-sujeito representadas na Formação Discursiva do consumidor.

O comercial inicia apresentando uma mão que pega um livro:

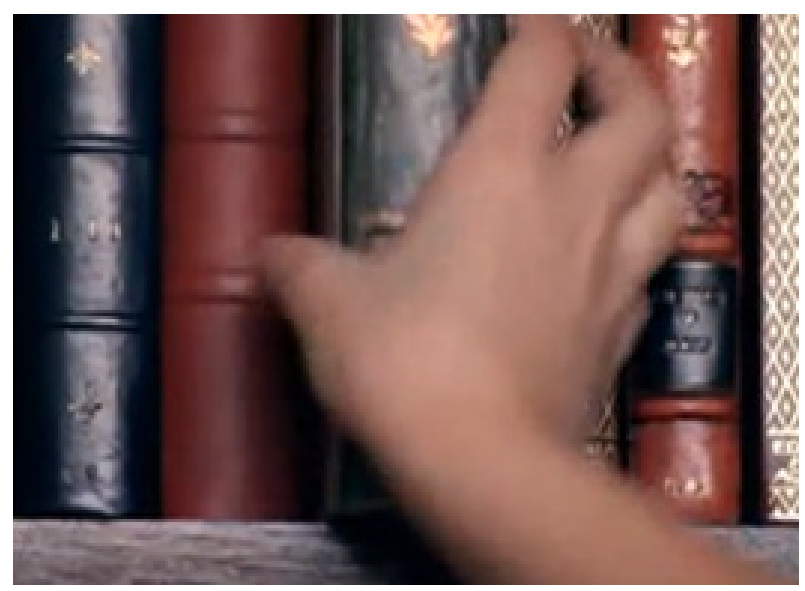

Figura 1: Recorte do Comercial

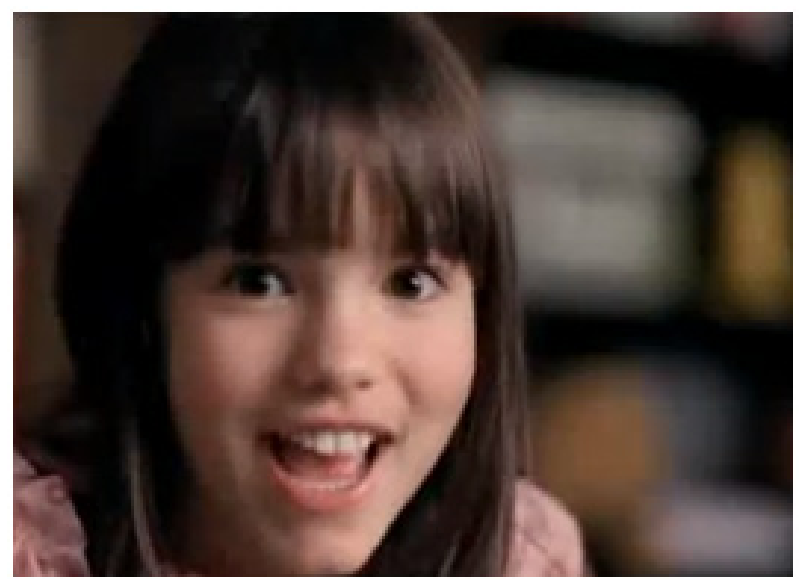

Figura 2: Recorte do Comercial

Observemos os livros (SD1) e a mão (SD2). Quais as características da SD1: livros novos ou antigos? E quais as características da SD2: uma mão jovem? Que formação imaginária podemos depreender dessas SDs: quem fala para quem? De que lugar? Quando discriminamos elementos constituintes da imagem, essa é uma operação de recorte do analista que, de acordo com Quevedo (2012), secciona a imagem em partes que julga relevantes destacar, por isso, denominar "secção discursiva" (SD), visto que não cabe a noção de linearidade de leitura implicada pelo termo sequência.

Muito rapidamente, uma menina aparece e enuncia (Figura 2):

No dicionário, familia é um grupo de pessoas unidas pelo laço de sangue. Na vida real, não é bem assim. 
Na vida real, no senso comum, costumamos tomar o dicionário como detentor do saber, o lugar onde todas as nossas dúvidas sobre ortografia e os sentidos das palavras são respondidas. O dicionário é o lugar onde a língua é guardada e estabilizada. No entanto, sob o ponto de vista em que pensamos os dicionários, não é bem assim. Compreendendo o dicionário como um "objeto discursivo" (NUNES, 2006), ele se torna discurso, logo, produz efeitos de sentidos, está sujeito a falhas, contradições, deslizes, sendo passível de ser interpretado sob determinadas condições de produção sócio-histórico-ideológicas. No comercial, o livro (SD1) retirado da estante pela menina é antigo, desses clássicos de capas duras avermelhadas, tal como as enciclopédias (Barsa ou Britânica, para citar dois exemplos), famosas no século passado, que costumavam enfeitar as estantes de muitas famílias brasileiras.

O comercial utiliza-se do dicionário para definir família, contrapondo-se, entretanto, a ele. $\mathrm{Na}$ figura 01, podemos perceber a mão pegando um dos livros que apresentam características de antigos e/ou desatualizados. Seria aí uma crítica aos dicionários? Estaria o sentido de família representado na SD1 como ultrapassado? Ou estaria o dicionário não acompanhando a evolução da língua em seu uso social?

O dicionário interpela os sujeitos de forma a definir o que é certo ou errado no que diz respeito ao sentido das palavras, sua escrita etc. Quando usamos o dicionário? Em determinados momentos em que queremos saber como se escreve determinada palavra ou quando precisamos de alguma definição, mas, nessas situações, pouco se reflete sobre o sentido que a palavra procurada possui em determinadas condições de produção ${ }^{14}$. Isso se comprova a partir do enunciado: "na vida real não é bem assim”. Como se o dicionário não fosse produzido na vida real. Petri (2010), em Um outro olhar sobre o dicionário, explicita que os dicionários são produzidos na vida real e que devemos "desconstruir a imagem de lugar de interdito da dúvida". De acordo com a autora,

\begin{abstract}
[...] a fim de que possamos lançar um outro olhar sobre o dicionário e para que possamos trabalhar, de fato, com a produção de sentidos, precisamos exercer nosso direito de crítica e defender o direito de nossos alunos de terem acesso às "metáforas". O homem que é capaz da "metáfora" é mais do que um mero reprodutor de ideias, ele trabalha no espaço possível da transformação, espaço no qual os sentidos podem ser outros (PETRI, 2010, p. 23).
\end{abstract}

Os enunciados a seguir, presentes no comercial, explicitam movimentos de sentidos: Na vida real não é assim.

Na vida real não é bem assim.

Essas construções provocam efeitos de sentido diferenciados, centrados no uso dos advérbios "não" e "bem". Ao empregar "na vida real não é bem assim", o comercial deixa em aberto, pelo uso de "bem," que pode ser assim em determinadas representações de família e diferente em outras. Além disso, nessas condições de produção, há uma necessidade de exprimir sentido diferente daquele do dicionário, pois o comercial procura mostrar uma família além daquela referida no dicionário, a da "na vida real". Esse novo sentido que propõe o comercial, retomando o já regularizado pelo dicionário, provoca uma atualização da memória do sujeito telespectador: essa família que você conhece, a partir de uma memória dicionarista, não é assim, porque "na vida real não é bem assim". De acordo com Pêcheux (2010b, p. 56): 
[...] uma memória não poderia ser concebida como uma esfera plena, cujas bordas seriam transcendentais históricos e cujo conteúdo seria um sentido homogêneo, acumulado ao modo de um reservatório: é necessariamente um espaço móvel de divisões, de disjunções, de deslocamentos e de retomadas, de conflitos de regularização... um espaço de desdobramentos, réplicas, polêmicas e contradiscursos.

Essa reformulação do discurso sobre o que é ou não é família abre possibilidades para uma atualização da memória: faz com que a noção de família se desloque e que o sujeito telespectador passe a confrontar sua posição com outra, como se o fato de consumir produtos da Sadia pudesse fazer com que as famílias fossem todas iguais. É a memória em funcionamento, atualizando-se, deslocando, produzindo sentidos outros.

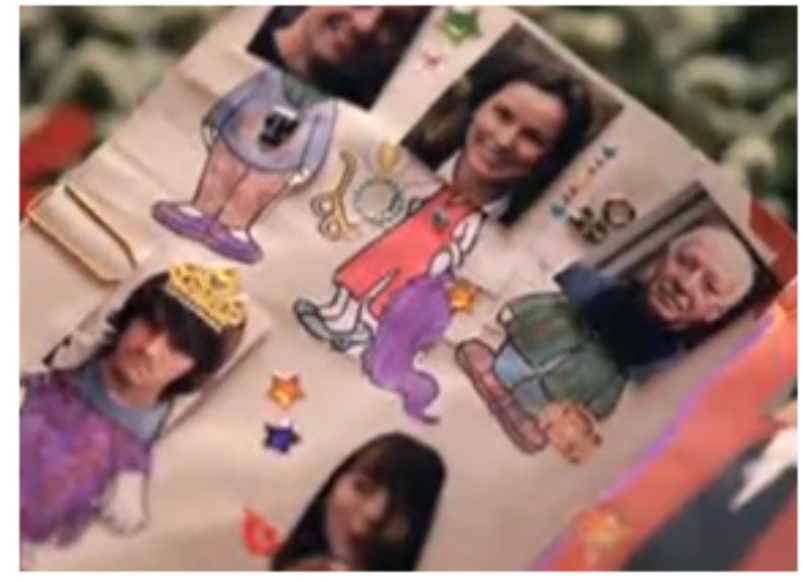

Figura 3: Recorte do Comercial

$\mathrm{Na}$ sequência do comercial, a menina apresenta um diário de uma adolescente com uma árvore genealógica (SD3) com fotos de pessoas felizes. Isso implica dizer que o livro antigo não se tratava de um dicionário, mas de um diário de uma jovem menina. Jovem nas concepções, mas ligada à memória do antigo, do tradicional, pois, ao final do comercial, aparece a imagem da união/ reunião de um menino e uma menina como a promessa de uma nova família, isso aparece no livro também pelas imagens das fotos. Fato que nos possibilita afirmar que, apesar de trazer uma representação nova ao conceito de família, o comercial assume uma posição sujeito que se vale tanto da Formação Discursiva "moderna" pelo antigo, como "contemporânea" pelo novo que virá.

A SD 3 representa a família sanguínea. No entanto, observamos que, ao contrário das árvores desse tipo, as fotos não estão interligadas por linhas, provocando um efeito de sentido diverso daquele proposto pelo comercial, o que "na vida real não é bem assim". Podemos perceber nessa figura que o jogo ideológico está na dissimulação dos efeitos de sentido sob a forma de um sentido único: família é a união por laços de sangue. No entanto, esses laços podem não estar presentes para também ser família. Essa representação imaginária é, segundo Althusser (s.d.), a ideologia que interpela os sujeitos a tomarem um determinado lugar na sociedade, e que cria a "ilusão" de liberdade do sujeito. Assim, temos a ilusão de unidade do discurso, de que nos apropriamos desse discurso e fazemos uma leitura, esquecendo de que há outras possíveis leituras. Além disso, podemos perceber que todos os membros da família estão com algum bem material, demonstrando o incentivo que comerciais dão para o desejo do consumo.

$\mathrm{Na}$ sequência do comercial, a menina narra, exemplificando as diferentes famílias que cada um daqueles que estão no diário possui, mostrando que a vida, como ela é, extrapola os sentidos contidos nos dicionários. A língua, assim, sob nosso gesto interpretativo discursivo, não é um sistema perfeito, ela extrapola seus limites, falha, desliza, ela é incompleta. E é aí que encontramos espaço para compreender o funcionamento da língua em sua materialidade. Novos sentidos que emergem sem desconsiderar a memória da família sanguínea, àquela dos dicionários.

Eu tenho uma familia que todo mundo tem dez. anos. 


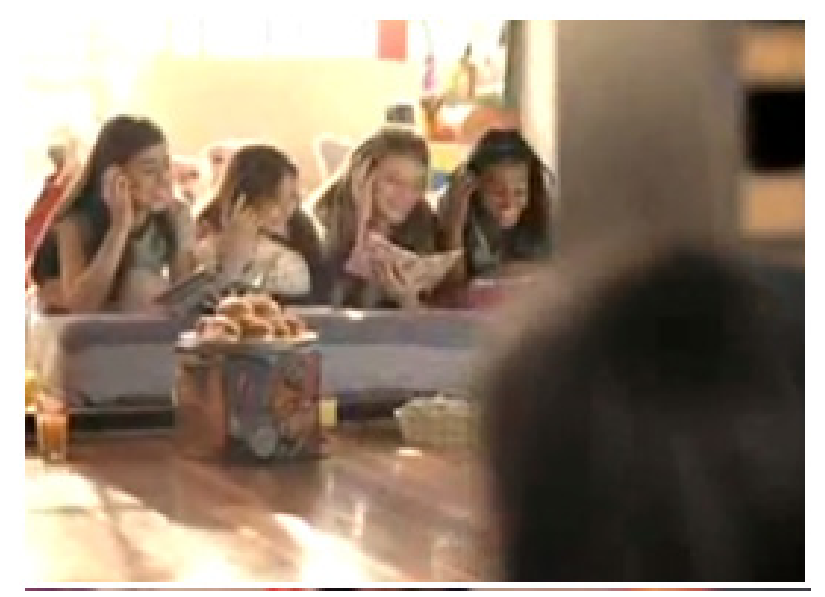

Figura 4: Recorte do Comercial

Meu avô tem uma família que só se encontra às terças [pausa] e outra, às quintas.

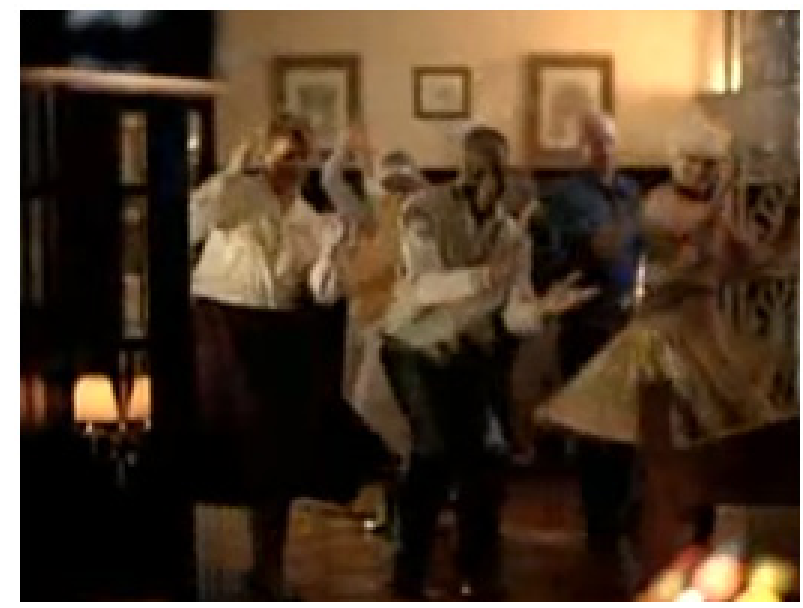

Figura 5: Recorte do Comercial

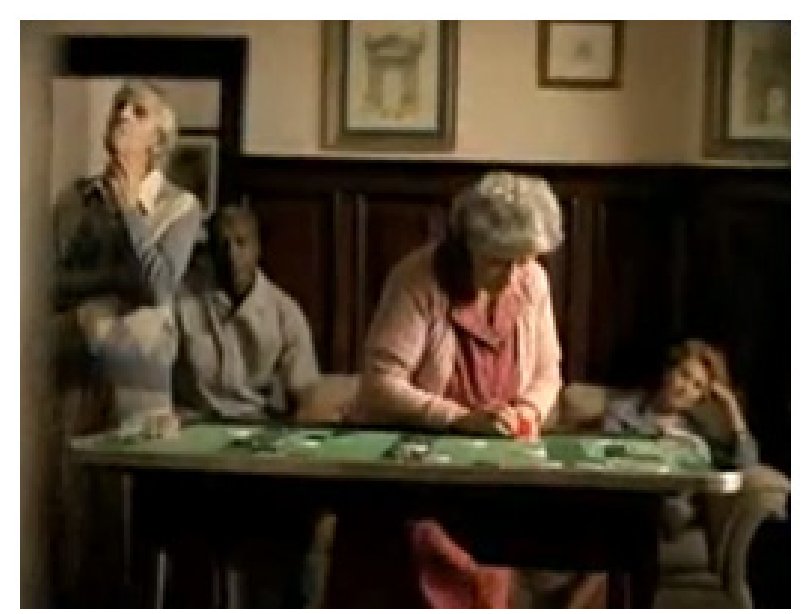

Figura 6: Recorte do Comercial

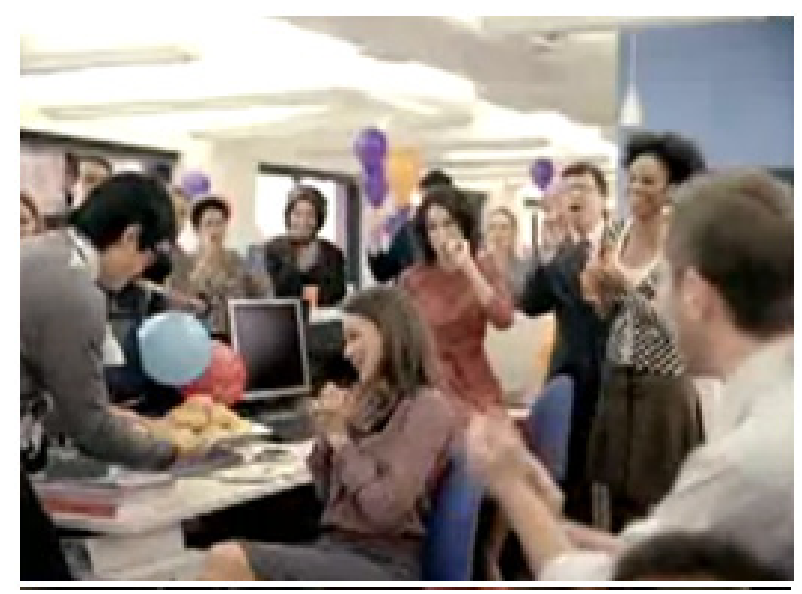

Figura 7: Recorte do Comercial

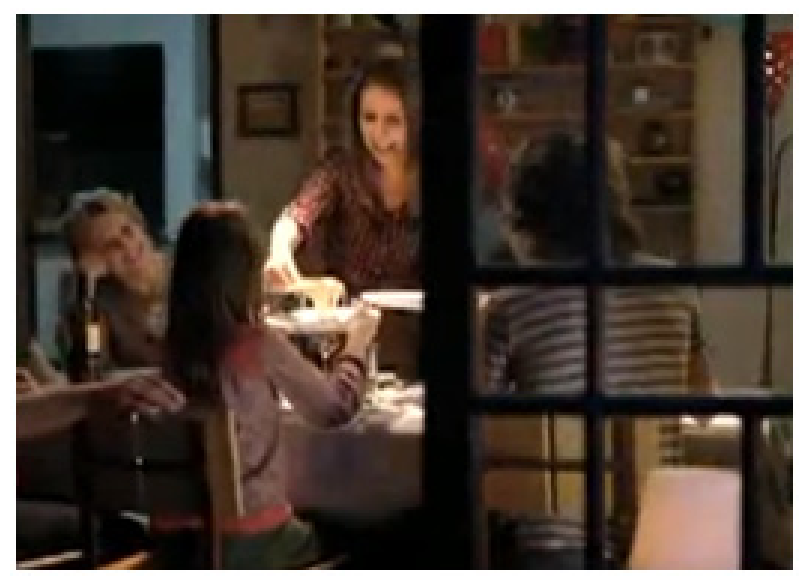

Figura 8: Recorte do Comercia

Meu irmão tem uma família esquisita que a gente nunca vê.

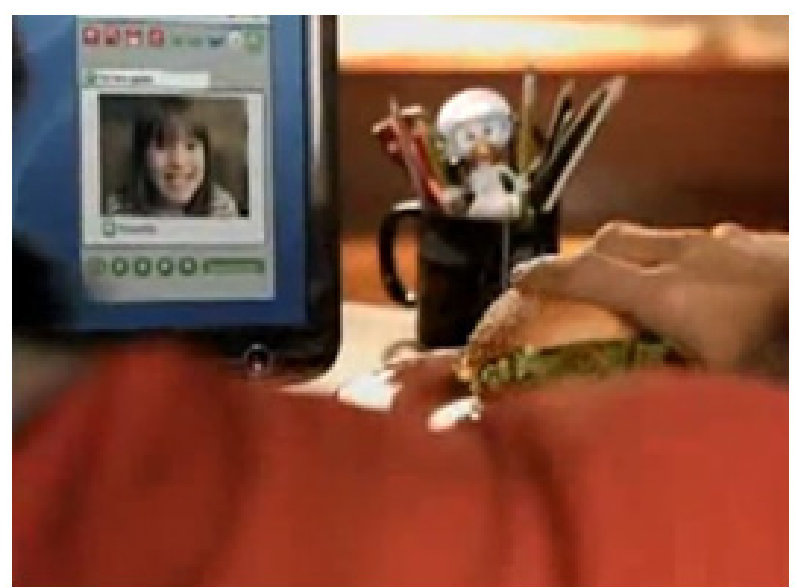

Figura 9: Recorte do Comercia

Minha mãe tem uma familia de dia e outra de noite. 
Em todas as figuras, isto é, em todas as famílias que, de acordo com a peça publicitária, são deixadas de fora do dicionário, a comida está presente, seja em lanches rápidos, festas, jantares, sempre de forma acessível. No entanto, é na figura 9 que o ícone da Sadia surge de surpresa ao sujeito telespectador, retomando na memória, por meio dessa metonímia, que se trata de um comercial da Sadia, mesmo sem o nome da marca aparecer. De acordo com Azevedo (2014, p. 325) é na metonímia que o sujeito marca o desejo, "que é sempre desejo daquilo que falta". A metonímia marca, nessa peça publicitária, o desejo de uma família perfeita aliado ao desejo de facilidade para alimentação e este, por sua vez, une-se ao desejo da Sadia: de que todos comprem e consumam seus produtos e sejam felizes.

Lembremos que o desejo, na acepção psicanalítica, é o que move o homem. Ao longo da vida, o homem busca suprir suas necessidades e carências no desejo, tanto nas relações pessoais quanto nas relações de consumo, advindas da ruptura sofrida e da sensação de castração que carrega, de maneira inconsciente, perseguindo um estado de satisfação, de prazer e de conforto. Por isso, como um ser insaciado, o sujeito busca, incansavelmente, o consumo para suprir esse desejo.

De acordo com Medeiros (2013, p. 54), a mídia (enquanto produtora de objetos de consumo) produz para o mercado (e suas relações de poder no seio social) e opera a partir de um lugar capitalista, fazendo-nos consumidores de desejos artificiais propostos pelo sistema. A mídia aproveita-se disso e atua na esfera do imaginário, pois vende não só o produto, mas também aquilo que ele significa ou representa, levando em conta o momento social, o desejo, o prazer, o poder, a sexualidade etc. "O sujeito do inconsciente é permanentemente desejoso, faltante e singular", acrescenta Lima (2002, p. 64).

$\mathrm{Na}$ sequência do comercial, observemos a estrutura linguística adotada para enumerar as diferentes formações de família, de cada membro familiar, da menina como mostradas no decorrer das figuras anteriormente apresentadas:

\section{Eu tenho uma familia que todo mundo tem dez anos.}

Meu avô tem uma família que só se encontra às terças [pausa] e outra, às quintas.

Minha mãe tem uma família de dia e outra de noite.

Meu irmão tem uma família esquisita que a gente nunca vê.

Todos os enunciados, com exceção do terceiro, possuem Sujeito + Verbo (ter) + Objeto (uma família) + oração introduzida por pronome relativo. Essa recorrência provoca um efeito de sentido no sujeito telespectador, pois, independente de sua faixa etária, ele se enquadra em alguma dessas situações: jovens de dez anos, idosos, trabalho, casa, amigos virtuais, todos estão representados ${ }^{15}$. Nesse sentido, a relativa determinativa, introduzida pelo pronome relativo "que", provoca o aparecimento do efeito de préconstruído, aquilo que remete a uma construção anterior, exterior, mas sempre independente do que é construído pelo enunciado. Trata-se do efeito discursivo ligado ao encaixe sintático, de acordo com Pêcheux (1988).

$\mathrm{O}$ referido autor explica que o efeito de encadeamento do pré-construído, assim como o efeito de articulação, é determinado materialmente na própria estrutura do interdiscurso. Nesse sentido, o efeito de préconstruído é uma realização do interdiscurso no intradiscurso, introduzindo o diferente: a afirmação de o sujeito ter uma família, composta 
por pai, mãe e filhos, é da ordem de uma Formação Discursiva tradicional e hegemônica; já o que é apresentado na relativa situa-se em outro âmbito, abrindo espaço para saberes advindos de outras Formações Discursivas, tomando aqui a Formação Discursiva como heterogênea a si mesma. Portanto, no caso desse comercial, diferentes famílias são apresentadas, não somente as de sangue, mas também as outras possíveis na sociedade "contemporânea".

Já que o comercial inicia negando a representação de família apresentada pelo dicionário, precisa, pois, afirmar o que entende por família:

Familia é como plural de gente.

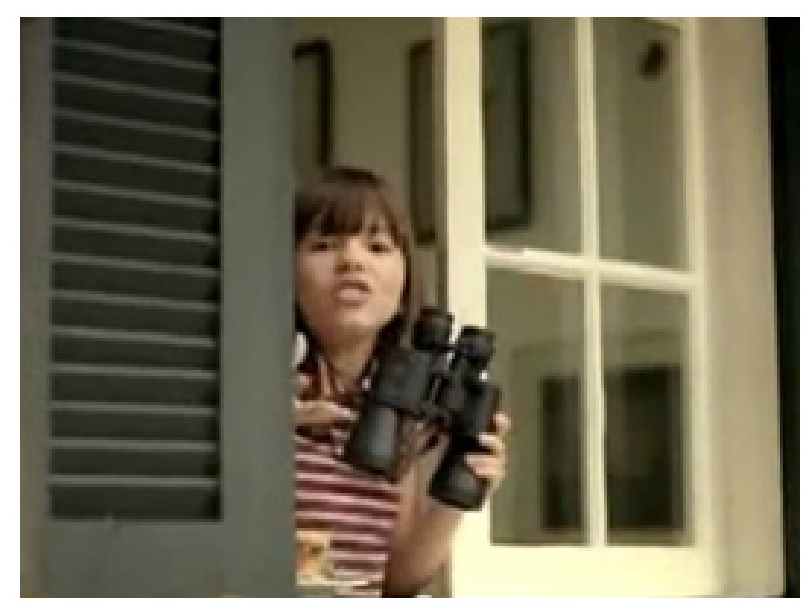

Figura 10: Recorte do Comercial

A menina, na figura 10, com binóculos nas mãos, mostra como o sujeito telespectador pode ver longe, saindo das fronteiras do dicionário, fazendo com que se retome na memória, por meio de uma comparação, que família pode ser "como plural de gente", metonimicamente, remetendo ao "S" da marca que define família. uma manada de pais...

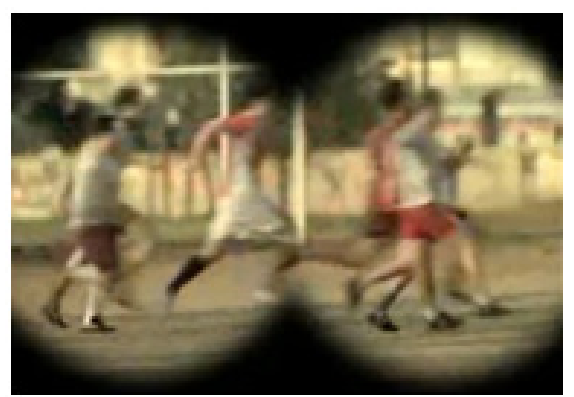

Figura 11: Recorte do Comercial

um enxame de pirralbos...

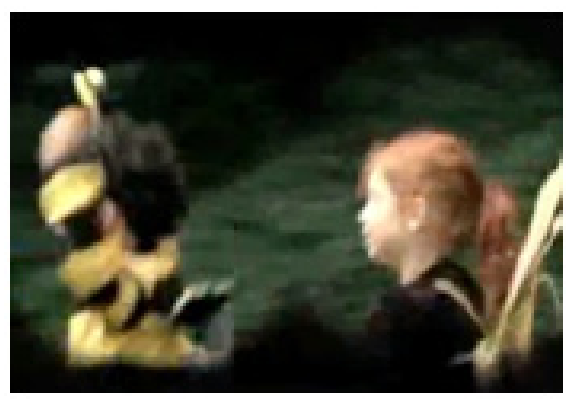

Figura 12: Recorte do Comercial

ou um cardume de comadres

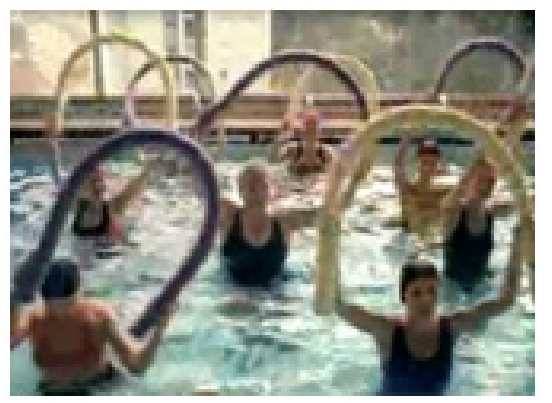

Figura 13: Recorte do Comercial

$\mathrm{Na}$ figura 11, assim como na figura 13, a peça publicitária desumaniza, propõe, por meio dos coletivos "manada" (figura 11) e "cardume" (figura 13) que as pessoas se movimentam todas em mesma direção, construindo um imaginário de que as famílias, sejam elas como forem - de búfalos ou de peixes -, devem movimentar-se na mesma direção e unidos. $\mathrm{O}$ mesmo acontece na figura 12, mas, nesse caso o coletivo é formado para representar crianças fantasiadas, promovendo um meio de identificação do sujeito 
telespectador via imagem.

mas quando chega o Domingo... todo mundo fica no plural... e todas as familias viram... uma só

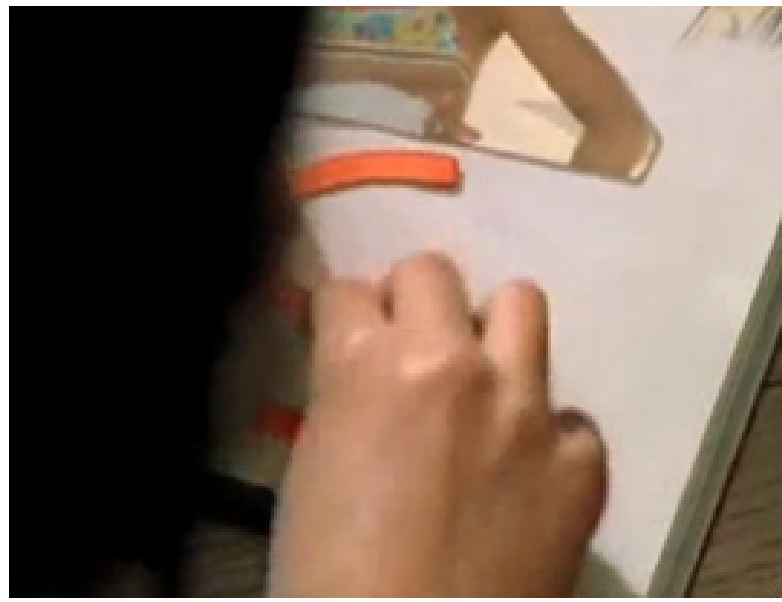

Figura 14: Recorte do Comercial

Para fechar, o discurso do monólogo funciona de modo circular, já que a menina, em seu monólogo, retorna àquilo que todo mundo sabe: um tradicional almoço familiar no domingo. Ao mesmo tempo em que retoma na memória o plural formado pela letra $\mathrm{S}$ - assim como a marca sendo divulgada -, provoca, em seu efeito de fechamento, o sentido de que família é: todas aquelas como indicadas na peça publicitária. Nesse momento, o volume da música aumenta e o trecho "it's everywhere, you just have to care!" 16 ganha destaque, relacionando-se ao monólogo, constituindo-se enquanto discurso, provocando um efeito de sentido de fechamento que confirma o que realmente importa na opinião da peça publicitária: o amor.

Observemos a sequência discursiva: "Família é como plural de gente".

Nesse enunciado, o comercial inicia um percurso para o seu final em que compara a família a um grupo de pessoas ou grupo de animais, rompendo com o sedimento em sociedade que se (re)produz na memória do sujeito. $\mathrm{O}$ anúncio parece instaurar o diferente, o estranho, aquilo que produz a desestabilização nas redes de memória; no caso, a possibilidade de novas constituições familiares. Há um trabalho de leitura que opera no nível discursivo por meio do uso de palavras no coletivo (manada, enxame, cardume), invocando agrupamento, mas são complementados por designações pertinentes aos seres humanos: pais, pirralhos e comadres. Tais construções relacionam-se de forma parafrástica com o "plural de gente", fazendo furo na rede de memória, no imaginário de família, não assumindo relações afetivas ainda negadas pela sociedade.

$\mathrm{Na}$ sequência, em "mas quando chega o Domingo... todo mundo fica no plural... e todas as famílias viram... uma só", o comercial utilizase de uma conjunção coordenativa adversativa (mas) para atribuir ênfase ao que se propõe o comercial: divulgar a marca. No entanto, provoca um efeito de sentido de adição, somando a ideia de que, para a família de "todo mundo", não importa o que se passou na semana, porque, no Domingo, todas se unem para um almoço em família. Essa conjunção admite as diferenças que se estão operando na família contemporânea, mostrando a univocidade na pluralidade: as famílias são todas iguais independentemente daqueles que a constituem e o que importa, pois, não é o sangue, mas a relação de afeto que há entre as pessoas que consomem sempre os produtos da Sadia. Dessa maneira, a representação de família desse comercial apresenta uma tentativa de igualar famílias na diferença dos grupos e não na estrutura familiar convencional.

Assim, o comercial em análise apresenta uma Formação Discursiva em que a representação de família se dá pela seguinte posição-sujeito: a de que a família, para se constituir família, não 
necessita somente de laços sanguíneos - como foi dito nos primeiros segundos da peça publicitária. Os diferentes lugares sociais ocupados pelos membros da família tradicional - por exemplo, a mãe é a mesma colega do trabalho, amiga, chefe, filha, esposa, tia etc. - formam novos agrupamentos, novos núcleos, enfim, novas "famílias". Importante, no entanto, perceber que não são mencionadas estruturas familiares formadas por homossexuais, uma questão bastante discutida na contemporaneidade. Essa falta denuncia a presença do preconceito na sociedade que o comercial evita expor explicitamente, para não constranger os possíveis consumidores. É um jogo interessante e astuto que se estabelece: os homossexuais enquadramse na diferença apresentada no anúncio, mas não são referidos explicitamente. Isso possibilita sua identificação e, consequentemente, pode tornálos consumidores da marca.

Para encerrar o comercial, o slogan da marca aparece incentivando as pessoas a comprarem os produtos Sadia, não só pelo fato de serem ou não gostosos, mas também motivando os sujeitos a partir do desejo de felicidade e de união, como se um produto fosse capaz de unir as pessoas.

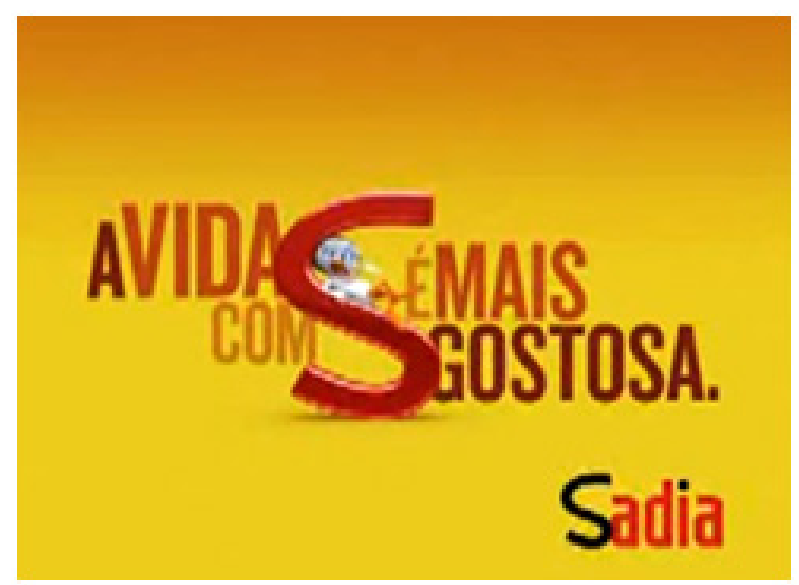

Figura 15: Recorte do Comercial

Essa imagem (Figura 15) faz a retomada de tudo o que foi apresentado no comercial. Se ainda restar alguma dúvida, ela será sanada no fechamento e a ordem que fica é: Compre Sadia! Consuma Sadia!

\section{Considerações finais}

A vida com $\mathrm{S}$ de Sadia é mais gostosa, ou a vida das famílias no plural é mais gostosa? Que desejo é esse que o comercial almeja despertar ou saciar? O desejo de que as pessoas percebam que dão mais atenção ao mundo do trabalho, dos grupos sociais, do que a quem está ao seu redor do dia-a-dia? Ou o desejo de consumo? Por meio da compra dos produtos da Sadia, as pessoas conseguirão alcançar o gostoso da vida? E que gostoso é esse?

A partir do nosso gesto interpretativo na análise dessa peça publicitária, podemos perceber que a representação de família no comercial, inicialmente, apresenta uma representação de família enquanto ideal (diário, família reunida para jantar), a música (retomando no interdiscurso amor de pai, mãe, filho e filha); por outro lado, ele vai além, apresentando reflexões que permitem abrir possibilidades para diferentes representações de familia: há os amigos, os colegas de trabalho, os companheiros de clube, a família de dia e outra de noite etc., demonstrando assim, outra Formação Ideológica, a da família "contemporânea".

A família, segundo alguns dizeres populares, é o nosso bem mais precioso, aquilo de que necessitamos para sobreviver. Nascemos, crescemos, aprendemos a ser quem somos em meio às famílias, sejam representadas por pessoas do mesmo sangue ou apenas por vínculos afetivos. Pensar sobre essa temática é pensar sobre nossa vida, é refletir sobre o que nos constitui primeiro como sujeitos para, futuramente e/ou ao mesmo tempo, nos constituirmos como sujeitos (FLORES, 2014).

Pensar sobre os discursos - da música, 
do monólogo, das imagens - de uma peça publicitária, que trata de algo tocante para qualquer sujeito, é fazer movimentar sentidos que cada um separadamente provoca, mas que unidos permitem tantos outros possíveis gestos interpretativos. Tentamos mostrar, na análise dessa peça publicitária, que o sentido pode ser um, mas pode ser outro, que o discurso circula de forma incessante e que a língua é nosso material de análise. Nada e nenhum deles funciona isoladamente, não há um único sentido para família, assim como não há uma única interpretação possível para essa peça publicitária que analisamos. Fica assim, ao final desta reflexão, a pergunta: Mas afinal o que é família? Para o anúncio publicitário, são todos aqueles enquadrados nas relações permissíveis socialmente que consomem os produtos Sadia! Os outros ... não vêm ao caso!

\section{Referências}

ALTHUSSER, L. Ideologia e Aparelhos ideológicos do Estado. Editorial Presença, Martins Pontes, s.d.

AZEVEDO, Aline Fernandes de. Sentidos do corpo: metáfora e interdiscurso. Linguagem em (Dis)curso - LemD, Tubarão, SC, v. 14, n. 2, p. 321-335, maio/ago. 2014. Disponível em: <http://www.scielo.br/pdf/ld/v14n2/15187632-ld-14-02-00321.pdf>. Acesso em: 01 ago. 2017.

BRASIL. Estatuto da Família. Disponível em: $<$ http://www.neca.org.br/images/PL\%2065832013.pdf > . Acesso em: 01 ago. 2017.

BERNSTEIN, Eduardo. Sadia estreia nova campanha da marca. Disponível em: <http://www.memoriadapropaganda.org.br/
Noticias/Noticia.php?newsId=20090808B\&I mg=22009 > . Acesso em: 01 jun. 2014.

FLORES, Lucas Martins. Você se vê naquilo que vê? Representações de família em comerciais e seus efeitos de sentidos. 2014. 109 f. Dissertação (Mestrado em Letras). Universidade Católica de Pelotas UCPEL, Pelotas, BR, 2014.

LIMA, Elisane Pinto da Silva Machado de. Se formos fiéis a ele, ele certamente será fiel a nós: a condicionalidade e o discurso religioso da Igreja Universal do Reino de Deus. Dissertação (Mestrado em Letras). Universidade Católica de Pelotas - UCPEL, Pelotas, BR, 2002.

MEDEIROS, Caciane Souza de. Sociedade da Imagem: a (re)produção de sentidos da mídia do espetáculo. Santa Maria: UFSM, PPGL-Editores, 2013.

NUNES, José Horta. Dicionários no Brasil: análise e história - do século XVI ao XIX. Campinas: Pontes Editores; São Paulo: FAPESP; São José do Rio Preto: FAPERP. 2006.

PÊCHEUX, Michel. Semântica e discurso: uma crítica à afirmação do óbvio. Tradução Eni Puccinelli Orlandi. Campinas: Unicamp, 1988.

- Análise Automática do Discurso (AAD69). IN: GADET, Françoise; HAK, Tony. (Org.) Por uma análise automática do discurso: uma introdução à obra de Michel Pêcheux. Tradução Bethania S. Mariani. 4. ed. Campinas, SP: Unicamp, 2010a.

Papel da Memória. In: ACHARD, Pierre et al. Papel da Memória. Tradução José Horta Nunes, 3. ed. Campinas, SP: Pontes, 2010b. 
PETRI, Verli. Um olhar sobre o dicionário: a produção de sentidos. 1. ed. Santa Maria: UFSM, PPGL-Editores, 2010.

QUEVEDO, M. Q. de. Do Gesto de reparar a(à) gestão de sentidos: um exercício de análise da imagem com base na Análise de Discurso. 2012. 253 f. Dissertação (Mestrado em Letras). Universidade Católica de Pelotas - UCPEL, 2012.

ROUDINESCO, E. A família em desordem. Tradução André Telles. Rio de Janeiro: Jorge Zahar. 2003.

Submissão em 09/08/2017 Aceito em 25/08/2017 